\title{
CARACTERIZAÇÃO MORFOMÉTRICA DO CAMARÃO SETE-BARBAS, Xiphopenaeus kroyeri (Heller, 1862), (CRUSTACEA: DECAPODA: PENAEIDAE), CAPTURADO NO NORDESTE DO BRASIL
}

\author{
Carlos Tassito Corrêa IVO \\ Pesquisador do CNPq. \\ Maria do Carmo Ferrão SANTOS \\ Bióloga do CEPENE/IBAMA
}

\begin{abstract}
RESUMO
A pesca artesanal de camarão com barcos motorizados na região Nordeste do Brasil teve inicio em 1969, na área de pesca em frente ao Pontal do Peba (estado de Alagoas), expandindo-se posteriormente por outras áreas da plataforma continental, entre os estados do Maranhão e Bahia. O camarão setebarbas, Xiphopenaeus kroyeri (HELLER, 1862), é a espécie mais abundante entre os peneídeos capturados na região, alcançando a média de $70,0 \%$ dos desembarques. No presente trabalho são apresentadas algumas medidas de tendência central e de dispersão de comprimento e peso para indivíduos capturados em diferentes áreas de pesca da região e analisadas algumas correlações entre medidas de comprimento e entre medidas de peso e o comprimento. Indivíduos capturados na área de influência do rio São Francisco (estados de Alagoas e Sergipe) e na área de influência dos rios Mamucabas e Ilhetas (estado de Pernambuco) possuem, em geral, comprimentos e pesos médios estatisticamente iguais. Os indivíduos capturados na área de influência dos rios Curimataú e Guajú (estado do Rio Grande do Norte) são estatisticamente menores e menos pesados do que os indivíduos capturados nas demais áreas. Em geral, não foram encontradas diferenças estatísticas significantes entre os coeficientes angulares das equações estimadas para correlacionar medidas de comprimento, e medidas de peso e comprimento do camarão sete-barbas capturado nas áreas influência do rio São Francisco e rios Mamucabas e Ilhetas, mas os coeficientes angulares destas equações são, em geral, estatisticamente diferentes dos coeficientes estimados para as equações dos indivíduos capturados na área de influência dos rios Curimataú e Guajú.

Palavras-Chave: Camarão, Xiphopenaeus kroyer, Decapoda, captura.
\end{abstract}

\begin{abstract}
Morphometric Characteristics of the Shrimp Xiphopenaeus kroyeri (Heller, 1862), (Crustacea: Decapoda: Penaeidae) catched in Northeast Brazil

Fishing for shrimp on powerboat in Northeast Brazil begun in 1969 off Alagoas State coast, and it was soon extended to the area between Maranhão and Bahia States. The seabob shrimp, Xiphopenaeus kroyeri (HELLER, 1862), is the most abundant species caught in Northeast Brazil, averaging $70,0 \%$ of the
\end{abstract}


penaeid total catches. On this paper some measures of central tendency and dispersion are estimated for length and weight (total, carapace and abdomen) of seabob caught in the São Francisco area river (Alagoas and Sergipe States), Mamucabas and Ilhetas rivers (Pernambuco State) and Curimataú and Guajú rivers area (Rio Grande do Norte State). It also presents some regression equations for length measures and for weight and length measures. Individuals caught in the area of São Francisco river (Alagoas and Sergipe States) and Mamucabas and Ilhetas rivers (Pernambuco State) have length and weight statistically equal, but they are statistically heavier and larger than those caught in Curimataú and Guajú rivers area (Rio Grande do Norte State). No statistic difference on angular regression coefficient for length measures, and weight/length measures were found to exist for most equations estimated for individuals caught in the São Francisco river area and Mamucabas and Ilhetas rivers area, but they are statistically different from those estimated for regressions of individuals caught in Curimataú and Guajú areas.

Key words: Shrimp, Xiphopenaeus kroyer, Decapoda, catch.

\section{INTRODUÇÃO \\ O camarão sete-barbas, Xiphopenaeus kroyeri (Heller, 1862) é} encontrado em toda costa atlântica ocidental desde o estado da Virgínia - USA até o estado do Rio Grande do Sul - Brasil (D’INCAO,1995), sendo, portanto, uma espécie tropical, com distribuição contínua (COELHO, RAMOS-PORTO \& KOENING, 1980).

Em toda sua área de ocorrência, o camarão sete-barbas destaca-se pela importância sócio-econômica e volume das capturas, bastante relevante entre os recursos camaroeiros marinhos.

A produção mundial de peneídeos alcançou a média de 700 mil toneladas/ano durante a década de 80 (GULLAND \& ROTHSCHIELD, 1984), passando, na primeira metade da década de 90, para cerca de 1,8 milhões de toneladas/ano (ALVERSON et. al., 1994). Estima-se que, na década de 90, a captura anual de by catch (ou fauna acompanhante) da pesca de camarão atingiu cerca de 11,2 milhões de toneladas/ano, com aproximadamente 85,0\% destes peixes já mortos, devolvidos ao mar (ALVERSON, op. cit.).

No Brasil, a estimativa é que a pesca de peneídeos atingiu $40.5 \mathrm{mil}$ toneladas no ano de 1997, sendo a região Nordeste responsável por 44,0 \% desta produção (IBAMA/CEPENE, 1998).

No Nordeste do Brasil a pesca artesanal do camarão, com barcos motorizados, teve inicio em 1969 na região do Pontal do Peba no estado de Alagoas, expandindo-se rapidamente por outras áreas da plataforma continental brasileira, entre os estados do Maranhão e Bahia (COELHO \& SANTOS, 1994/95).

Com uma produção que atinge cerca de $70,0 \%$ dos peneídeos desembarcados no Nordeste brasileiro, o camarão sete-barbas é a principal espécie de peneídeo capturado na região. Nas regiões Sudeste, Sul e Norte, a 
produção da espécie foi estimada respectivamente em $67,3 \%, 24,6 \%$ e 1,0\% da produção total desembarcada. Estudos mais recentes realizados em áreas de pesca do camarão sete-barbas no litoral sul de Pernambuco e Alagoas indicam que o camarão sete-barbas representa $65,5 \%$ do peso da biomassa capturada, contribuindo, porém, com apenas $23,7 \%$ da receita gerada com a pesca de peneídeos; nesta região, o preço médio de comercialização atinge baixo valores ( $\mathrm{R} \$ 1,50$ por quilo), se comparado com o preço das outras espécies (CARVALHO, OLIVEIRA \& CAMPOS). Por outro lado, o camarão branco, Litopenaeus schmitti (BURKENROAR, 1936) contribuiu com 72,2\% da receita gerada, embora tenha representado apenas $24,9 \%$ da produção total desembarcada. A receita econômica gerada pela pesca de peneídeos no nordeste brasileiro é superada apenas pelas pescarias de lagostas (SANTOS, 1994/95; PAIVA, 1996).

Uma descrição das embarcações utilizadas na pesca de camarão na Região Nordeste do Brasil pode ser encontrada em SANTOS (1997).

Apesar da importante posição ocupada pelo camarão sete-barbas nas capturas de pescado marinho do Nordeste brasileiro, nenhum trabalho foi desenvolvido com vistas à caracterização biométrica desta espécie em suas diferentes áreas de pesca da região. No presente trabalho são analisadas algumas correlações entre as medidas lineares de comprimento total, do cefalotórax e do abdome, e entre o peso e o comprimento de cada uma destas medidas. Ainda são apresentados alguns coeficientes angulares das equações de regressão obtidas para medidas de comprimento e de peso estimadas para a espécie capturada nos estados de Sergipe/Alagoas, Pernambuco e Rio Grande do Norte, com o objetivo de se verificar possíveis ocorrências de diferenciação intra-específica do camarão sete barbas na sua área de ocorrência nestes estados, fato que provocaria a existência de diferentes estoques do camarão na região.

\section{MATERIAL E MÉTODOS}

O material utilizado no presente trabalho foi obtido de amostras das capturas realizadas por barcos motorizados que operam nas localidades a seguir, durante o mês de julho de 1998: (a) estados de Sergipe (município de Pirambu) e Alagoas (município de Piaçabuçu) na área de influência do rio São Francisco, (b) estado de Pernambuco (município de Tamandaré) na área de influência dos rios Mamucabas e Ilhetas e (c) estado do Rio Grande do Norte (município de Baia Formosa) área de influência dos rios Curimataú e Guajú. Em cada uma das localidades de pesca foram amostrados 240 indivíduos (120 machos e 120 fêmeas), num total de 720 indivíduos. Para cada indivíduo amostrado, após a caracterização sexual, determinou-se o comprimento total individual -CT (medida entre a extremidade anterior do rostro e a extremidade posterior do telso) e o respectivo peso - PT. Em seguida, foram determinados o comprimento do cefalotórax - CC (medida entre a extremidade anterior do rostro e a margem posterior da carapaça), e o respectivo peso - PC, e o comprimento do abdome $\mathrm{CA}$ (medida entre a margem anterior do primeiro somito abdominal e a extremidade

Trab. Oceanog. Univ. Fed. PE, Recife, 27(1):129- 148, 1999. 
posterior do telso) e o respectivo peso - PA. As medidas de comprimento foram tomadas em milímetros, com um paquímetro de aço e aproximação de 0,1 milímetros. As medidas de peso foram tomadas em gramas, com uma balança digital eletrônica e precisão de 0,1 grama.

A caracterização de estoques populacionais pode ser feita a partir de diferenças identificadas nas características bioquímicas dos indivíduos que comporiam estes estoques, e através de diferenças encontradas nas características biológicas, morfométricas e merísticas dos indivíduos e na dinâmica populacional (SALES, 1997).

Tendo em vista as análises estatísticas desenvolvidas no presente trabalho, os dados de comprimento e peso foram distribuídos em intervalos de classes de 1,0mm de comprimento do cefalotórax.

Para a comparação das médias de comprimento ou peso de machos e fêmeas capturados em uma mesma localidade, ou em localidades diferentes, foi usado o teste " $\mathrm{t}$ " bilateral com $\propto=0,05$. Este teste também foi aplicado para comparar os coeficientes angulares das varias equações estimadas para machos e fêmeas capturados em uma mesma localidade, considerando-se também um teste bilateral, com $\propto=0,05$; quando a hipótese de nulidade Ho foi aceita (não se constatou diferenças estatísticas significantes entre coeficientes angulares), novas retas de regressão foram estimadas para representar a relação entre as medidas consideradas. As seguintes equações de regressão foram estimadas: comprimento total - CT/comprimento do cefalotórax - CC, comprimento do abdome - CA/comprimento do cefalotórax - CC, peso do cefalotórax PC/comprimento do cefalotórax - CC, peso total - PT/comprimento do cefalotórax $\mathrm{CC}$, peso do abdome - PA/comprimento do cefalotórax - CC, comprimento do abdome - CA/comprimento total - CT, peso total - PT/comprimento total - CT, peso do abdome - PA/comprimento do abdome - CA, comprimento do cefalotórax - CC/comprimento total - CT, comprimento do cefalotórax - CC/comprimento do abdome - CA e comprimento total - CT/comprimento do abdome - CA.

A comparação entre coeficientes angulares de regressões estimadas para as mesmas medidas em diferentes localidades foi feita através do teste $\mathrm{F}$ bilateral com $\propto=0,05$. Quando a hipótese de nulidade Ho foi rejeitada (existe diferença estatística significante entre pelo menos dois coeficientes testados), o Mult Rang Teste (Neuman Keuls) foi aplicado para que se verificasse quais médias são diferentes entre si, com $\mathrm{q}=0,05$. Os coeficientes angulares das seguintes equações foram testados, por sexo: comprimento do abdome - CA/comprimento do cefalotórax - CC, peso do cefalotórax - PC/comprimento do cefalotórax - CC, peso total - PT/comprimento do cefalotórax $\mathrm{CC}$, peso do abdome $\mathrm{PA}$ /comprimento do cefalotórax $\mathrm{CC}$, comprimento do abdome CA/comprimento total - CT, peso total - PT/comprimento total - CT e peso do abdome/comprimento do abdome - CA.

Para correlacionar duas medidas de comprimento, os dados foram ajustados a equação linear de regressão do tipo $y=a+b x$, e as relações entre 132 
peso e comprimento foram correlacionadas pela equação exponencial do tipo y $=\mathrm{A}$ xb. Os valores dos coeficientes angulares e lineares para todas as equações foram estimados pelo método dos mínimos quadrados.

Todas as análises estatísticas foram feitas segundo ZAR (1984) e IVO \& FONTELES-FILHO (1997).

\section{RESULTADOS E DISCUSSÃO}

No presente trabalho, determinou-se o percentual existente entre o comprimento do cefalotórax e o abdome, dos indivíduos como um todo; os valores para ambos os sexos foram bastante semelhantes nas diferentes localidades, ficando em torno de 28,0 e 72,0\%, respectivamente. Análise idêntica procedeu-se com relação ao peso dos indivíduos, onde também não se verificou diferença entre os sexos, ficando o peso da cefalotórax com média de 40,0\% e do abdome com $60,0 \%$.

Nos peneídeos, uma parte do primeiro somito abdominal penetra sob a margem posterior da cefalotórax. Portanto, para cada classe de comprimento levou-se em consideração dois indivíduos, verificando que, no camarão setebarbas este percentual não ultrapassa a 5,0\% do comprimento do abdômen, enquanto o telso representa entre 15 e $23,0 \%$ do comprimento do abdome. $\mathrm{O}$ rostro do camarão sete-barbas (de sua base à extremidade distal) eqüivale em torno de 10 a $22,0 \%$ a mais que o valor do comprimento do seu cefalotórax (da base do rostro à extremidade posterior do cefalotórax), talvez, por esta razão, no litoral brasileiro a espécie também é nominada popularmente de chifrudo, espigão e espigudo.

As medidas de comprimento e peso do camarão sete-barbas no Nordeste brasileiro apresentaram as medidas de dispersão por localidades de pesca e sexo, descritas a seguir e agrupadas na tabela 1.

(a) Área de influência do rio São Francisco

Machos - comprimento do cefalotórax (CC) entre 12,0mm e 23,0mm, com média de 17,6 e desvio padrão de 2,3mm; peso do cefalotórax (PC) entre $0,4 \mathrm{~g} \mathrm{e}$ $2,4 \mathrm{~g}$, com média de $1,2 \mathrm{~g}$ e desvio padrão de $0,4 \mathrm{~g}$; comprimento total (CT) entre $59,0 \mathrm{~mm}$ e $100,0 \mathrm{~mm}$, com média de 82,8 e desvio padrão de $9,7 \mathrm{~mm}$; peso total (PT) entre $1,4 \mathrm{~g}$ e $6,0 \mathrm{~g}$, com média de $3,3 \mathrm{~g}$ e desvio padrão de $1,1 \mathrm{~g}$; comprimento do abdome (CA) entre $34,0 \mathrm{~mm}$ e $57,0 \mathrm{~mm}$, com média de 47,0 e desvio padrão de $5,6 \mathrm{~mm}$; peso do abdome (PA) entre $0,9 \mathrm{~g}$ e $3,7 \mathrm{~g}$, com média de $2,1 \mathrm{~g}$ e desvio padrão de $0,7 \mathrm{~g}$.

Fêmeas - comprimento do cefalotórax (CC) entre 9,0mm e 29,0mm, com média de 19,5 e desvio padrão de 5,2mm; peso do cefalotórax (PC) entre $0,2 \mathrm{~g}$ e $5,2 \mathrm{~g}$, com média de 2,0g e desvio padrão de 1,3g; comprimento total (CT) entre $45,0 \mathrm{~mm}$ e $121,0 \mathrm{~mm}$, com média de 88,6 e desvio padrão de $21,2 \mathrm{~mm}$; peso total (PT) entre $0,5 \mathrm{~g}$ e $11,4 \mathrm{~g}$, com média de $4,9 \mathrm{~g}$ e desvio padrão de $2,9 \mathrm{~g}$; comprimento do abdome (CA) entre $22,0 \mathrm{~mm}$ e $69,0 \mathrm{~mm}$, com média de 48,9 e desvio padrão de $11,4 \mathrm{~mm}$; peso do abdome (PA) entre $0,3 \mathrm{~g}$ e $6,4 \mathrm{~g}$, com média de $2,8 \mathrm{~g}$ e desvio

Trab. Oceanog. Univ. Fed. PE, Recife, 27(1):129- 148, 1999. 
padrão de 1,6g.

(b) Área de influência dos rios Mamucabas e Ilhetas

Machos - comprimento do cefalotórax (CC) entre 14,0mm e 24,0mm, com média de 18,6 e desvio padrão de $2,6 \mathrm{~mm}$; peso do cefalotórax (PC) entre $0,4 \mathrm{~g} \mathrm{e}$ $3,0 \mathrm{~g}$, com média de $1,5 \mathrm{~g}$ e desvio padrão de $0,6 \mathrm{~g}$; comprimento total (CT) entre $66,0 \mathrm{~mm}$ e $111,0 \mathrm{~mm}$, com média de 88,4 e desvio padrão de $10,9 \mathrm{~mm}$; peso total (PT) entre $1,7 \mathrm{~g}$ e $4,6 \mathrm{~g}$, com média de $4,4 \mathrm{~g}$ e desvio padrão de $1,6 \mathrm{~g}$; comprimento do abdome (CA) entre $37,0 \mathrm{~mm}$ e $66,0 \mathrm{~mm}$, com média de 50,8 e desvio padrão de 6,6mm; peso do abdome (PA) entre $1,2 \mathrm{~g}$ e 3,3g, com média de $3,1 \mathrm{~g}$ e desvio padrão de $2,9 \mathrm{~g}$.

Fêmeas - comprimento do cefalotórax (CC) entre 9,0mm e 27,0mm, com média de 18,1 e desvio padrão de 4,0mm; peso do cefalotórax (PC) entre $0,1 \mathrm{~mm}$ e $3,8 \mathrm{~g}$, com média de $1,1 \mathrm{~g}$ e desvio padrão de $0,6 \mathrm{~g}$; comprimento total (CT) entre $46,0 \mathrm{~mm}$ e $113,0 \mathrm{~mm}$, com média de 86,1 e desvio padrão de $15,3 \mathrm{~mm}$; peso total (PT) entre $0,4 \mathrm{~g}$ e $9,9 \mathrm{~g}$, com média de $2,9 \mathrm{~g}$ e desvio padrão de $1,6 \mathrm{~g}$; comprimento do abdome (CA) entre $27,0 \mathrm{~mm}$ e $68,0 \mathrm{~mm}$, com média de 48,9 e desvio padrão de $8,3 \mathrm{~mm}$; peso do abdome (PA) entre $0,3 \mathrm{~g}$ e $6,1 \mathrm{~g}$, com média de $1,8 \mathrm{~g}$ e desvio padrão de $1,0 \mathrm{~g}$.

(c) Área de influência dos rios Curimataú e Guajú

Machos - comprimento do cefalotórax (CC) entre 12,0mm e 24,0mm, com média de 17,1 e desvio padrão de $2,7 \mathrm{~mm}$; peso do cefalotórax (PC) entre $0,3 \mathrm{~g}$ e $1,8 \mathrm{~g}$, com média de $0,8 \mathrm{~g}$ e desvio padrão de $0,4 \mathrm{~g}$; comprimento total (CT) entre $60,0 \mathrm{~mm}$ e $98,0 \mathrm{~mm}$, com média de 80,9 e desvio padrão de $10,0 \mathrm{~mm}$; peso total (PT) entre $0,9 \mathrm{~g}$ e $4,0 \mathrm{~g}$, com média de $2,2 \mathrm{~g}$ e desvio padrão de $0,8 \mathrm{~g}$; comprimento do abdome (CA) entre $33,0 \mathrm{~mm}$ e $85,0 \mathrm{~mm}$, com média de 46,8 e desvio padrão de 7,0mm; peso do abdome (PA) entre $0,6 \mathrm{~g}$ e 3,0g, com média de $1,4 \mathrm{~g}$ e desvio padrão de $0,5 \mathrm{~g}$.

Fêmeas - comprimento do cefalotórax (CC) entre 12,0mm e 25,0mm, com média de 17,9 e desvio padrão de $2,5 \mathrm{~mm}$; peso do cefalotórax (PC) entre $0,3 \mathrm{~g}$ e $2,2 \mathrm{~g}$, com média de $1,0 \mathrm{~g}$ e desvio padrão de $0,4 \mathrm{~g}$; comprimento total (CT) entre $61,0 \mathrm{~mm}$ e $106,0 \mathrm{~mm}$, com média de 84,4 e desvio padrão de $10,6 \mathrm{~mm}$; peso total (PT) entre $0,8 \mathrm{~g}$ e $5,7 \mathrm{~g}$, com média de $2,5 \mathrm{~g}$ e desvio padrão de $0,9 \mathrm{~g}$; comprimento do abdome (CA) entre $32,0 \mathrm{~mm}$ e $57,0 \mathrm{~mm}$, com média de 46,6 e desvio padrão de $5,1 \mathrm{~mm}$; peso do abdome (PA) entre $0,5 \mathrm{~g}$ e $3,5 \mathrm{~g}$, com média de $1,6 \mathrm{~g}$ e desvio padrão de $0,5 \mathrm{~g}$.

Para o litoral do estado de São Paulo, RODRIGUES et al. (1992) estimaram a relação biométrica do camarão sete-barbas, entre valores médios de peso total e de comprimento total, obtendo-se as seguintes expressões: WT $=3,00345.10-3$ LT3,247002 (para machos) e WT = 3,074184.10-3 LT3,2314 (para fêmeas).

Os testes "t" ( $\mathrm{n} 1=\mathrm{n} 2=120, \propto=0,05$ e tcrit. $=1,96)$ aplicados para comparar as médias de uma mesma variável de comprimento, por sexo, para indivíduos amostrados em uma mesma localidade, indicam não existir diferença estatística significante entre as médias de comprimento do cefalotórax e 
comprimento total obtidas para machos e fêmeas na área de influência dos rios Mamucabas e Ilhetas e de comprimento do abdômen na área de influência do rio São Francisco e área de influência dos rios Curimataú e Guajú. Diferenças estatísticas significantes, com predomínio das fêmeas, foram observadas para as medidas de comprimento do cefalotórax e comprimento total na área de influência do rio São Francisco e área de influência dos rios Curimataú e Guajú e comprimento do abdome, com predomínio dos machos, na área de influência dos rios Mamucabas e Ilhetas. No que concerne às medidas de peso, diferenças estatísticas significativas, com predomínio das fêmeas, foram observadas para peso do cefalotórax, peso total e peso do abdome na área de influência do rio São Francisco e área de influência dos rios Curimataú e Guajú. Na área de influência dos rios Mamucabas e Ilhetas também foram observadas diferenças estatísticas significantes entre estas medidas, porém com predomínio dos machos (tabela 1).

Tabela 1 - Medidas de dispersão estimadas para machos e fêmeas do camarão sete-barbas, Xiphopenaeus kroyeri (Heller, 1862), capturado nos estados de Sergipe e Alagoas (área de influência do rio São Francisco), Pernambuco (área de influência dos rios Formoso e Ilhetas) e Rio Grande do Norte (área de influência dos rios Curimataú e Guajú). Valores de "t" estimados para comparação das médias de machos e fêmeas.

\begin{tabular}{|c|c|c|c|c|c|c|c|}
\hline & \multicolumn{6}{|c|}{ Medidas de dispersão } & \multirow{3}{*}{$t_{\text {cal }}$} \\
\hline \multirow[t]{2}{*}{ Variáveis } & \multicolumn{2}{|c|}{ amplitude } & \multicolumn{2}{|c|}{ média } & \multicolumn{2}{|c|}{ desvio padrão } & \\
\hline & macho & fêmea & macho & fêmea & macho & fêmea & \\
\hline \multicolumn{8}{|c|}{ Área de influência do rio São Francisco } \\
\hline $\mathrm{CC}$ & $12,0-23,0$ & $9,0-29,0$ & 17,6 & 19,5 & 2,3 & 5,2 & 3,684 \\
\hline $\mathrm{PC}$ & $0,4-2,4$ & $0,2-5,2$ & 1,2 & 2,0 & 0,4 & 1,3 & 6,438 \\
\hline CT & $\begin{array}{c}59,0- \\
100,0\end{array}$ & $\begin{array}{c}45,0- \\
121,0\end{array}$ & 82,8 & 88,6 & 9,7 & 21,2 & 2,723 \\
\hline PT & $1,4-6,0$ & $0,5-11,4$ & 3,3 & 4,9 & 1,1 & 2,9 & 5,417 \\
\hline $\mathrm{CA}$ & $34,0-57,0$ & $22,0-69,0$ & 47,0 & 48,9 & 5,6 & 11,4 & 1,663 \\
\hline PA & $0,9-3,7$ & $0,3-6,4$ & 2,1 & 2,8 & 0,7 & 1,6 & 4,440 \\
\hline \multicolumn{8}{|c|}{ Área de influência dos rios Formoso e Ilhetas } \\
\hline $\mathrm{CC}$ & $14,0-24,0$ & $9,0-27,0$ & 18,6 & 18,1 & 2,6 & 4,0 & $-1,230$ \\
\hline $\mathrm{PC}$ & $0,4-3,0$ & $0,1-3,8$ & 1,5 & 1,1 & 0,6 & 0,6 & $-5,333$ \\
\hline CT & $\begin{array}{c}66,0- \\
111,0\end{array}$ & $\begin{array}{r}46,0- \\
113,0\end{array}$ & 88,4 & 86,1 & 10,9 & 15,3 & $-1,377$ \\
\hline PT & $1,7-4,6$ & $0,4-9,9$ & 4,4 & 2,9 & 1,6 & 1,6 & $-7,434$ \\
\hline CA & $37,0-66,0$ & $27,0-68,0$ & 50,8 & 48,9 & 6,6 & 8,3 & $-2,034$ \\
\hline PA & $1,2-3,3$ & $0,3-6,1$ & 3,1 & 1,8 & 2,9 & 1,0 & $-4,852$ \\
\hline \multicolumn{8}{|c|}{ Área de influência dos rios Curimataú e Guajú } \\
\hline $\mathrm{CC}$ & $12,0-24,0$ & $12,0-25,0$ & 17,1 & 17,9 & 2,7 & 2,5 & 2,128 \\
\hline $\mathrm{PC}$ & $0,3-1,8$ & $0,3-2,2$ & 0,8 & 1,0 & 0,4 & 0,4 & 3,590 \\
\hline CT & $60,0-98,0$ & $\begin{array}{c}61,0- \\
106,0\end{array}$ & 80,9 & 84,4 & 10,0 & 10,6 & 2,633 \\
\hline PT & $0,9-4,0$ & $0,8-5,7$ & 2,2 & 2,5 & 0,8 & 0,9 & 2,641 \\
\hline CA & $33,0-85,0$ & $32,0-57,0$ & 46,8 & 46,6 & 7,0 & 5,1 & $-0,284$ \\
\hline PA & $0,6-3,0$ & $0,5-3,5$ & 1,4 & 1,6 & 0,5 & 0,5 & 2,419 \\
\hline
\end{tabular}


Os maiores comprimentos e pesos médios observados para machos na área de influencia dos rios Mamucabas e Ilhetas, ao contrário do que se observa para as demais áreas, devem estar associados com maior amplitude de comprimento observada para as fêmeas, com razoável ocorrência na amostra de indivíduos menores do que 14,0mm de comprimento do cefalotórax, menor comprimento de macho na amostra.

Os testes "t" $(\mathrm{n} 1=\mathrm{n} 2=240, \propto=0,05$ e tcrit. $=1,96)$. aplicados para a comparação das médias de comprimento de uma mesma variável de comprimento, para indivíduos amostrados em diferentes localidades, independente de sexo, indicam não existir diferença estatística significante entre as médias de comprimento do cefalotórax, comprimento total e comprimento do abdome quando se compara indivíduos provenientes de amostras realizadas na área de influência do rio São Francisco e na área de influência dos rios Mamucabas e Ilhetas e, entre comprimento total e comprimento do abdome quando se compara indivíduos provenientes de amostras realizadas na área de influência do rio São Francisco e na área de influência dos rios Curimataú e Guajú.

Diferenças estatísticas significativas foram observadas para as médias de comprimento do cefalotórax, com predomínio dos indivíduos provenientes de amostras realizadas na área de influência do rio São Francisco em relação aos indivíduos capturados na área de influência dos rios Curimataú e Guajú. Também foram observadas diferenças estatísticas significantes para as médias de comprimento do cefalotórax, comprimento total e comprimento do abdome, com predomínio dos indivíduos capturados na área de influencia dos rios Mamucabas e Ilhetas em relação aos indivíduos capturados na área de influência dos rios Curimataú e Guajú. No que concerne as medidas de peso, ainda comparando as médias uma mesma medida, não foram observadas diferenças estatísticas significantes para peso total e peso do abdome, quando os indivíduos amostrados foram provenientes da área de influência do rio São Francisco e área de influência dos rios Mamucabas e Ilhetas. Ainda considerando estas áreas, diferença estatística significante foi observada para o peso total, com predomínio dos indivíduos provenientes das amostras realizadas na área de influência do rio São Francisco. As médias de peso do cefalotórax, peso total e peso do abdome determinadas para as amostras obtidas da área de influência do rio São Francisco e da área de influência dos rios Mamucabas e Ilhetas são maiores do que as respectivas médias obtidas para as amostras coletadas na área de influência dos rios Curimataú e Guajú (tabela 2).

O comprimento e, principalmente, o peso individual de uma mesma espécie em diferentes localidades, devem estar associados com a quantidade de alimento disponível, entre outras caraterísticas ambientais; áreas com maior disponibilidade de alimentos deverão apresentar indivíduos maiores e mais pesados. PAIVA (1997) faz referência à maior densidade da biomassa e peso do 
caranguejo-uçá nos estuários de Sergipe, incluindo o estuário do rio São Francisco, em relação a outros estuários do Nordeste do Brasil, atribuindo este fato a maior riqueza de matéria orgânica na região dos estuários de Sergipe. O mesmo fenômeno pode ser responsável pelo maior comprimento e peso médio do camarão sete-barbas capturado na área de influência do rio São Francisco e área de influência dos rios Mamucabas e Ilhetas, quando comparado aos indivíduos capturados na área de influência dos rios Curimataú e Guajú, se considerarmos que as fases iniciais da vida do camarão ocorre na região estuarina.

Tabela 2 - Valores estimados da média e desvio padrão (dp) e valores calculados de "t" para comparação de médias estimadas nas área de influência do rio São Francisco (1), área de influência dos rios Formoso e Ilhetas (2) e área de influência dos rios Curimataú e Guajú (3).

\begin{tabular}{|c|c|c|c|c|c|c|c|c|c|}
\hline & \multicolumn{9}{|c|}{ Áreas } \\
\hline \multirow[t]{2}{*}{ Variáveis } & \multicolumn{2}{|c|}{1} & \multicolumn{2}{|c|}{2} & \multicolumn{2}{|c|}{3} & \multicolumn{3}{|c|}{$\mathrm{t}$} \\
\hline & média & $\mathrm{dp}$ & média & $\mathrm{dp}$ & média & $\mathrm{dp}$ & $1-3$ & $1-2$ & $2-3$ \\
\hline $\mathrm{CC}$ & 18,6 & 4,1 & 18,3 & 3,4 & 17,5 & 2,6 & 0,478 & 2,383 & 2,109 \\
\hline $\mathrm{PC}$ & 1,6 & 1,0 & 1,3 & 0,6 & 0,9 & 0,4 & 3,096 & 7,392 & 5,852 \\
\hline $\mathrm{CT}$ & 85,7 & 16,7 & 87,3 & 13,3 & 82,7 & 10,4 & $-0,806$ & 1,680 & 2,980 \\
\hline $\mathrm{PT}$ & 4,1 & 2,3 & 3,6 & 1,8 & 2,4 & 0,9 & 1,726 & 7,715 & 7,168 \\
\hline CA & 47,9 & 9,0 & 49,9 & 7,5 & 46,7 & 6,1 & $-1,777$ & 1,241 & 3,536 \\
\hline PA & 2,5 & 1,3 & 2,5 & 1,3 & 1,5 & 0,5 & 0,011 & 7,819 & 4,616 \\
\hline
\end{tabular}

Os estudos das relações biométricas foram bastante utilizados na caracterização de espécies, raças e grupos populacionais, porém, sua importância tem sido minimizada, devido à evolução dos métodos de identificação através de caracteres genéticos, determinantes diretos das características fisiológicas e morfológicas dos indivíduos de uma população. Atualmente, esses estudos têm sido utilizados, fundamentalmente, para se identificar como os indivíduos de uma população reagem às modificações no meio ambiente e a fatores externos que modificam a estrutura populacional, como por exemplo o esforço de pesca, além de serem importantes na caracterização de modificações nas proporções corporais entre machos e fêmeas (IVO \& PEREIRA, 1996).

As equações de regressão estimadas para machos e fêmeas em cada uma das localidades de pesca, área de influência do rio São Francisco, área de influência dos rios Mamucabas e Ilhetas e, área de influência dos rios Curimataú e Guajú, apresentaram valores do coeficiente de correlação (r) superiores 0,993, sendo, portanto, significantes ao nível $\propto=0,05$. Os altos valores do coeficiente de correlação confirmam a existência de crescimento isométrico entre medidas de comprimento e alométrico entre medidas de peso e comprimento (tabelas 3 a 5).

Os coeficientes de determinação $\left(\mathrm{r}^{2}\right)$ mostram que as variações dos pontos y em torno da sua média, para todas as regressões estimadas, podem ser explicadas pela relação entre as variáveis y e x, com grau de certeza igual ou 
superior a $98,0 \%$.

Nas análises do teste "t" para a comparação dos coeficientes angulares das equações de regressão estimadas para machos e fêmeas, por localidade, foram observadas diferenças estatísticas significantes para as seguintes equações, portanto, com indicação da existência de dimorfísmo sexual:

(a) área de influência do rio São Francisco - comprimento do abdome $\mathrm{CA}$ /comprimento do cefalotórax $\mathrm{CC}$, comprimento do abdome - CA/comprimento total - CT, comprimento do cefalotórax - CC/comprimento do abdome - CA e comprimento total - CT/comprimento do abdome - CA (tabela 3).

Tabela 3 - Equações de regressão estimadas para machos e fêmeas do camarão sete-barbas, Xiphopenaeus kroyeri (Heller, 1862), capturados nos estados de Sergipe e Alagoas (área de influência do rio São Francisco) e valores estimados de "t" para comparação dos coeficientes angulares.

\begin{tabular}{l|l|l|r|l}
\hline Regressão & \multicolumn{2}{|c|}{ Equação } & \multicolumn{1}{c|}{$\mathrm{t}_{\text {cal }}$} & Conclusão \\
\hline & \multicolumn{1}{|c|}{ macho } & \multicolumn{1}{c}{ fêmea } & & \\
\hline CT/CC & $\mathrm{y}=16,309+3,745 \mathrm{x}$ & $\mathrm{y}=11,607+3,910 \mathrm{x})$ & $-0,749$ & aceita $\mathrm{H}_{\mathrm{o}}$ \\
CA/CC & $\mathrm{y}=5,964+2,345 \mathrm{x}$ & $\mathrm{y}=6,846+2,123 \mathrm{x}$ & 2,178 & rejeita $\mathrm{H}_{\mathrm{o}}$ \\
PC/CC & $\mathrm{y}=0,000591 \mathrm{x} 2,651$ & $\mathrm{y}=0,000576 \mathrm{x}, 704$ & 0,572 & aceita $\mathrm{H}_{\mathrm{o}}$ \\
PT/CC & $\mathrm{y}=0,001958 \mathrm{x} 2,590$ & $\mathrm{y}=0,001359 \mathrm{x} 2,651$ & $-0,120$ & aceita $\mathrm{H}_{\mathrm{o}}$ \\
PA/CC & $\mathrm{y}=0,001365 \mathrm{x} 2,560$ & $\mathrm{y}=0,000780 \mathrm{x}, 694$ & $-0,135$ & aceita $\mathrm{H}_{\mathrm{o}}$ \\
CA/CT & $\mathrm{y}=-3,349+0,615 \mathrm{x}$ & $\mathrm{y}=0,760+0,540 \mathrm{x}$ & 2,360 & rejeita $\mathrm{H}_{\mathrm{o}}$ \\
PT/CT & $\mathrm{y}=0,000003 \mathrm{x}^{3,146}$ & $\mathrm{y}=0,000004 \mathrm{x} 3,092$ & 0,351 & aceita $\mathrm{H}_{\mathrm{o}}$ \\
PA/CA & $\mathrm{y}=0,000027 \mathrm{x} 2,922$ & $\mathrm{y}=0,000013 \mathrm{x}, 109$ & $-1,210$ & aceita $\mathrm{H}_{\mathrm{o}}$ \\
CC/CT & $\mathrm{y}=-3,830+0,260 \mathrm{x}$ & $\mathrm{y}=-2,795+0,254 \mathrm{x}$ & 0,471 & aceita $\mathrm{H}_{\mathrm{o}}$ \\
CC/CA & $\mathrm{y}=-2,458+0,425 \mathrm{x}$ & $\mathrm{y}=-3,062+0,468 \mathrm{x}$ & $-2,097$ & rejeita $\mathrm{H}_{\mathrm{o}}$ \\
CT/CA & $\mathrm{y}=6,610+1,601 \mathrm{x}$ & $\mathrm{y}=-0,649+1,834 \mathrm{x}$ & $-2,499$ & rejeita $\mathrm{H}_{\mathrm{o}}$ \\
\hline ObS: Cof
\end{tabular}

Obs.: Coeficiente de correlação maiores do que 0,993; Número de pares ordenados igual a 11 para machos $\left(\mathrm{r}_{\text {crit }}=0,602\right)$ e 21 para fêmeas $\left(\mathrm{r}_{\text {crit }}=0,483\right)$, e $\mathrm{t}_{\text {crit }}=2,048$. Nos dois casos $\alpha=$ $0,05)$.

(b) área de influência dos rios Mamucabas e Ilhetas - comprimento total CT/comprimento do cefalotórax - CC, comprimento do abdome - CA/comprimento do cefalotórax - CC, peso total - PT/comprimento total - CT, peso do abdome $\mathrm{PA} /$ comprimento do abdome - CA, comprimento do cefalotórax - CC/comprimento total - CT e comprimento do cefalotórax - CC/comprimento do abdome - CA (tabela 4).

(c) área de influência dos rios Curimataú e Guajú - comprimento do total CT/comprimento do cefalotórax - CC, comprimento do abdome - CA/comprimento do cefalotórax - CC, comprimento do abdome - CA/comprimento total - CT, peso total - PT/comprimento total - CT, peso do abdome - PA/comprimento do abdome - CA, comprimento do cefalotórax - CC/comprimento do abdome - CA e comprimento total - CT/comprimento do abdome - CA (tabela 5). 
Tabela 4 - Equações de regressão estimadas para machos e fêmeas do camarão sete-barbas, Xiphopenaeus kroyeri (Heller, 1862), capturados no estado de Pernambuco (área de influência dos rios Formoso e Ilhetas) e valores estimados de "t" para comparação dos coeficientes angulares.

\begin{tabular}{|c|c|c|c|c|}
\hline \multirow{2}{*}{$\begin{array}{l}\text { Regressã } \\
\text { o }\end{array}$} & \multicolumn{2}{|c|}{ Equação } & \multirow[t]{2}{*}{$\mathrm{t}_{\mathrm{cal}}$} & \multirow[t]{2}{*}{ Conclusão } \\
\hline & macho & fêmea & & \\
\hline $\mathrm{CT} / \mathrm{CC}$ & $y=13,382+4,018 x$ & $\begin{array}{l}y=24,147+ \\
3,432 x\end{array}$ & 4,249 & rejeita $\mathrm{H}_{\mathrm{o}}$ \\
\hline $\mathrm{CA} / \mathrm{CC}$ & $y=5,445+2,445 x$ & $\begin{array}{l}y=12,552+ \\
1,957 x\end{array}$ & 5,269 & rejeita $\mathrm{H}_{\mathrm{o}}$ \\
\hline $\mathrm{PC} / \mathrm{CC}$ & $y=0,000423 x^{2,780}$ & $y=0,000287 x^{2,907}$ & $-1,213$ & aceita $\mathrm{H}_{\mathrm{o}}$ \\
\hline $\mathrm{PT} / \mathrm{CC}$ & $y=0,001917 x^{2,637}$ & $y=0,001811 x^{2,624}$ & 0,183 & aceita $\mathrm{H}_{\mathrm{o}}$ \\
\hline $\mathrm{PA} / \mathrm{CC}$ & $y=0,001553 x^{2,569}$ & $y=0,002131 x^{2,417}$ & 1,046 & aceita $\mathrm{H}_{\mathrm{o}}$ \\
\hline $\mathrm{CA} / \mathrm{CT}$ & $y=-2,793+0,610 x$ & $\begin{array}{l}y=-1,105+ \\
0,568 x\end{array}$ & 1,959 & aceita $\mathrm{H}_{0}$ \\
\hline $\mathrm{PT} / \mathrm{CT}$ & $y=0,000004 x^{3,106}$ & $\mathrm{y}=0,000001 \mathrm{x}^{3,443}$ & $-3,486$ & rejeita $\mathrm{H}_{\mathrm{o}}$ \\
\hline $\mathrm{PA} / \mathrm{CA}$ & $\mathrm{y}=0,000038 \mathrm{x}^{2,850}$ & $\mathrm{y}=0,000014 \mathrm{x}^{3,099}$ & $-2,600$ & rejeita $\mathrm{H}_{\mathrm{o}}$ \\
\hline $\mathrm{CC} / \mathrm{CT}$ & $y=-3,228+0,248 x$ & $\begin{array}{l}y=-6,829+ \\
0,289 x\end{array}$ & $-4,133$ & rejeita $\mathrm{H}_{\mathrm{o}}$ \\
\hline $\mathrm{CC} / \mathrm{CA}$ & $y=-1,938+0,403 x$ & $\begin{array}{l}y=-6,236+ \\
0,508 x\end{array}$ & $-5,726$ & rejeita $\mathrm{H}_{\mathrm{o}}$ \\
\hline $\mathrm{CT} / \mathrm{CA}$ & $y=5,064+1,631 x$ & $\begin{array}{l}y=2,467+ \\
1,749 x\end{array}$ & $-1,916$ & aceita $\mathrm{H}_{\mathrm{o}}$ \\
\hline
\end{tabular}

Obs.: Coeficiente de correlação maiores do que 0,993; número de pares ordenados (n) igual a 11 para machos $\left(r_{\text {crit }}=0,602\right)$ e 16 para fêmeas $\left(r_{\text {crit }}=0,497\right)$, e $t_{\text {crit }}=2,069$. Nos dois casos $\alpha$ $=0,05)$.

Tabela 5 - Equações de regressão estimadas para machos e fêmeas do camarão sete-barbas, Xiphopenaeus kroyeri (Heller, 1862), capturados no estado do Rio Grande do Norte (área de influência dos rios Curimataú e Gurjaú)

\begin{tabular}{l|l|l|c|l}
\hline $\begin{array}{l}|c| \\
\text { Regressã } \\
\mathrm{o}\end{array}$ & \multicolumn{2}{|c|}{ Equação } & $\mathrm{t}_{\text {cal }}$ & Conclusão \\
\hline & Macho & fêmea & & \\
\hline CT/CC & $\mathrm{y}=25,364+3,136 \mathrm{x}$ & $\mathrm{y}=16,532+3,732 \mathrm{x}$ & $-2,290$ & rejeita $\mathrm{H}_{\mathrm{o}}$ \\
CA/CC & $\mathrm{y}=8,763+2,147 \mathrm{x}$ & $\mathrm{y}=13,446+1,818 \mathrm{x}$ & 2,788 & rejeita $\mathrm{H}_{\mathrm{o}}$ \\
PC/CC & $\mathrm{y}=0,000729 \mathrm{x}^{2,374}$ & $\mathrm{y}=0,000540 \mathrm{x}^{2,576}$ & $-0,862$ & aceita $\mathrm{H}_{\mathrm{o}}$ \\
PT/CC & $\mathrm{y}=0,002534 \mathrm{x}^{2,734}$ & $\mathrm{y}=0,002293 \mathrm{x}^{2,391}$ & $-0,189$ & aceita $\mathrm{H}_{\mathrm{o}}$ \\
PA/CC & $\mathrm{y}=0,001824 \mathrm{x}^{2,319}$ & $\mathrm{y}=0,001971 \mathrm{x}^{2,264}$ & 0,482 & aceita $\mathrm{H}_{\mathrm{o}}$ \\
CA/CT & $\mathrm{y}=-7,085+0,666 \mathrm{x}$ & $\mathrm{y}=5,537+0,485 \mathrm{x}$ & 5,548 & rejeita $\mathrm{H}_{\mathrm{o}}$ \\
PT/CT & $\mathrm{y}=0,000001 \mathrm{x}^{3,313}$ & $\mathrm{y}=0,000006 \mathrm{x}^{2,900}$ & 2,610 & rejeita $\mathrm{H}_{\mathrm{o}}$ \\
PA/CA & $\mathrm{y}=0,000027 \mathrm{x}^{2,824}$ & $\mathrm{y}=0,000008 \mathrm{x}^{3,134}$ & $-2,144$ & rejeita $\mathrm{H}_{\mathrm{o}}$ \\
\hline
\end{tabular}

Trab. Oceanog. Univ. Fed. PE, Recife, 27(1):129- 148, 1999. 


\begin{tabular}{l|l|l|c|l}
\hline CC/CT & $y=-6,947+0,305 x$ & $y=-3,968+0,263 x$ & 2,896 & rejeita $\mathrm{H}_{o}$ \\
CC/CA & $y=-3,646+0,456 x$ & $y=-6,964+0,541 x$ & $-2,852$ & rejeita $\mathrm{H}_{\mathrm{o}}$ \\
CT/CA & $y=12,748+1,457 x$ & $\mathrm{y}=-11,007+2,052 \mathrm{x}$ & $-6,938$ & rejeita $\mathrm{H}_{\mathrm{o}}$ \\
\hline
\end{tabular}

Obs.: Coeficiente de correlação maiores do que 0,990; número de pares ordenados (n) igual a 12 para machos $\left(r_{\text {crit }}=0,576\right)$ e 14 para fêmeas $\left(r_{\text {crit }}=0,532\right)$, e $t_{\text {crit }}=2,074$. Nos dois casos $\alpha=0,05)$.

Diferenças estatísticas não significantes, não havendo, portanto dimorfísmo sexual, foram constatadas para as seguintes equações:

(a) área de influência do rio São Francisco - comprimento total - CT/comprimento do cefalotórax - CC, peso do cefalotórax - PC/comprimento do cefalotórax - CC, peso total - PT/comprimento do cefalotórax - CC, peso do abdome PA/comprimento do cefalotórax - CC, peso total - PT/comprimento total - CT, peso do abdome - PA/comprimento do abdome - CA e comprimento do cefalotórax - CC/comprimento total - CT (tabela 3).

(b) área de influência dos rios Mamucabas e Ilhetas - peso do cefalotórax PC/comprimento do cefalotórax - CC, peso total - PT/comprimento do cefalotórax $\mathrm{CC}$, peso do abdome - PA/comprimento do cefalotórax - CC, comprimento do abdome - CA/comprimento total - $\mathrm{CT}$ e comprimento total - CT/comprimento do abdome -CA (tabela 4).

(c) área de influência dos rios Curimataú e Guajú - peso do cefalotórax PC/comprimento do cefalotórax CC, peso total - PT/comprimento do cefalotórax $\mathrm{CC}$, peso do abdome - PA/comprimento do cefalotórax - $\mathrm{CC}$ e comprimento do cefalotórax - CC/comprimento total - CT (tabela 5).

Para cada uma destas relações estimou-se uma nova equação, considerando-se o conjunto machos mais fêmeas, todas com coeficientes angulares iguais ou superiores a 0,996 , portanto, significantes ao nível $\alpha=0,05$ (tabelas 6 a 8). Nestes casos, os valores de $r^{2}$ são ig uais ou superiores a 99,2 \%.

Tabela 6 - Equações de regressão estimadas para o camarão sete-barbas, Xiphopenaeus kroyeri (Heller, 1862), capturado nos estados de Sergipe e Alagoas (área de influência do rio São Francisco), quando os valores de " $t$ " indicaram a existência de diferenças entre os valores do coeficiente angular.

\begin{tabular}{|c|c|c|}
\hline Regressão & Equação & $\mathrm{r}$ \\
\hline $\mathrm{CT} / \mathrm{CC}$ & $\mathrm{y}=12,194+3,887 \mathrm{x}$ & $r=0,996$ \\
\hline $\mathrm{PC} / \mathrm{CC}$ & $y=0,000558 x^{2,705}$ & $r=0,998$ \\
\hline $\mathrm{PT} / \mathrm{CC}$ & $y=0,001462 x^{2,677}$ & $r=0,999$ \\
\hline $\mathrm{PA} / \mathrm{CC}$ & $y=0,000907 x^{2,657}$ & $\mathrm{r}=0,997$ \\
\hline $\mathrm{PT} / \mathrm{CT}$ & $y=0,000041 x^{3,085}$ & $\mathrm{r}=0,998$ \\
\hline $\mathrm{PA} / \mathrm{CA}$ & $y=0,000016 x^{3,068}$ & $\mathrm{r}=0,998$ \\
\hline $\mathrm{CC} / \mathrm{CT}$ & $y=-2,964+0,255 x$ & $r=0,996$ \\
\hline
\end{tabular}

Obs.: Número de pares ordenados igual a $21\left(\mathrm{r}_{\text {crit }}=0,483\right)$. 
Tabela 7 - Equações de regressão estimadas para o camarão sete-barbas, Xiphopenaeus kroyeri (Heller, 1862), capturado no estado de Pernambuco (área de influência dos rios Formoso e Ilhetas), quando os valores de "t" indicaram a existência de diferenças entre os valores do coeficiente angular.

\begin{tabular}{c|c|c}
\hline Regressão & Equação & $\mathrm{r}$ \\
\hline PC/CC & $\mathrm{y}=0,000336 \mathrm{x}^{2,866}$ & $\mathrm{r}=0,998$ \\
PT/CC & $\mathrm{y}=0,002545 \mathrm{x}^{2,523}$ & $\mathrm{r}=0,998$ \\
PA/CC & $\mathrm{y}=0,003050 \mathrm{x}{ }^{2,316}$ & $\mathrm{r}=0,998$ \\
CA/CT & $\mathrm{y}=1,695+0,547 \mathrm{x}$ & $\mathrm{r}=0,996$ \\
CT/CA & $\mathrm{y}=-2,424+1,816 \mathrm{x}$ & $\mathrm{r}=0,996$ \\
\hline
\end{tabular}

Obs.: Número de pares ordenados igual a $21\left(\mathrm{r}_{\text {crit }}=0,497\right)$. 
Tabela 8 - Equações de regressão estimadas para o camarão sete-barbas, Xiphopenaeus kroyeri (Heller, 1862), capturado no estado do Rio Grande do Norte (área de influência dos rios Curimataú e Guajú), quando os valores de "t" indicaram a existência de diferenças entre os valores do coeficiente angular.

\begin{tabular}{l|c|c}
\hline Regressão & Equação & $\mathrm{r}$ \\
\hline PC/CC & $\mathrm{y}=0,000626 \mathrm{x}^{2,526}$ & $\mathrm{r}=0,998$ \\
PT/CC & $\mathrm{y}=0,002687 \mathrm{x}^{2,342}$ & $\mathrm{r}=0,996$ \\
PA/CC & $\mathrm{y}=0,002295 \mathrm{x}^{2,222}$ & $\mathrm{r}=0,994$ \\
\hline
\end{tabular}

Obs.: Número de pares ordenados igual a $21\left(\mathrm{r}_{\text {crit }}=0,497\right)$.

Os trabalhos publicados para representar as relações existentes entre medidas do corpo do camarão sete-barbas capturado ao longo da costa brasileira estão restritos, principalmente, a equações que relacionam comprimento total, comprimento do cefalotórax e peso total.

NEIVA \& WISE (1967) verificaram não existir diferenças estatísticas significantes entre as equações comprimento do cefalotórax - mm (y)/ comprimento total - $\mathrm{mm}(\mathrm{x})$ e entre peso total - $\mathrm{w}(\mathrm{g}) /$ comprimento total - $\mathrm{mm}(\mathrm{x})$ para machos e fêmeas do camarão sete-barbas capturado no litoral do estado de São Paulo, optando por representar estas equações para o conjunto dos sexos como a seguir: $\mathrm{y}=-1,61+0,230 \mathrm{x}(\mathrm{r}=0,972)$ e $\log \mathrm{w}=4,996+3,34 \log \mathrm{x}$. RODRIGUES et al. (1992), ainda com base em dados coletados no litoral de São Paulo estimaram as seguintes equações $w=0,003003 \mathrm{x}^{3,247002} \mathrm{e} \mathrm{w}=0,003074 \mathrm{x}^{3,2314}$, respectivamente, para machos e fêmeas da espécie.

As equações peso total - $\mathrm{g}(\mathrm{w}) / \mathrm{comprimento} \mathrm{total}-\mathrm{cm}(\mathrm{x})$, estimadas para cada sexo do camarão sete-barbas capturado no litoral do estado do Paraná apresentaram diferenças estatisticamente significantes, de modo que as duas regressões estão representadas como a seguir para cada sexo: macho $\mathrm{w}=0,0075 \mathrm{x}$ 2,82 e fêmeas: $\mathrm{w}=0,00552 \times{ }^{2,98}$ (AMADO, 1978). Assim, a autora apresentou as seguintes expressões: $\mathrm{Lt}=12,05\left(1-\mathrm{e}^{-0,5487 . t}\right)$ e $\mathrm{Wt}=8,538\left(1-\mathrm{e}^{0,5487 .}\right)^{2,824}$, para machos $\mathrm{e}, \mathrm{Lt}=14,89\left(1-\mathrm{e}^{-0,6187 . t}\right) \mathrm{e} \mathrm{Wt}=17,22\left(1-\mathrm{e}^{0,6187 . t}\right)^{2,979}$. COELHO \& SANTOS (1993) estimaram as equações de regressão $\mathrm{CC}=0,223$ x (CT - 1,297) e CC $=0,265$ $\mathrm{x}(\mathrm{CT}-1,098)$ para machos e fêmeas do camarão sete-barbas capturado no litoral do estado de Pernambuco, onde $\mathrm{y}=$ comprimento do cefalotórax $\mathrm{e} \mathrm{x}=$ comprimento total.

A equação encontrada por PAIVA (1997) para a região Sudeste e Sul do Brasil, com relação ao peso e comprimento total foi a seguinte: $\mathrm{Wt}=3,039 \cdot 10^{-1 \mathrm{Lt}}$.

As análises do teste $\mathrm{F}$ para a comparação dos coeficientes angulares das equações de regressão estimadas para o camarão sete-barbas das três localidades consideradas no presente trabalho (área de influência do rio São Francisco, área de influência dos rios Mamucabas e Ilhetas e área de influência dos rios Curimataú e Guajú), independente de sexo, indicam a aceitação da hipótese de nulidade, portanto não existin do de diferenças estatísticas significantes $(\alpha=0,05)$ 
entre os coeficientes angulares, para as seguintes equações: Comprimento do abdome - CA/comprimento total - CT e peso do abdome - PA/comprimento do abdome - CA (tabelas 9 e 10).

Tabela 9 - Súmula dos testes F e Mult Range Test (Neuman Keuls), para comparação de coeficientes angulares da regressão CA/CT estimadas para machos e fêmeas do camarão sete-barbas, Xiphopenaeus kroyeri (Heller, 1862), capturados nos estados de Sergipe e Alagoas - área de influência do rio São Francisco (1), Pernambuco área de influência dos rios Formoso e Ilhetas (2) e Rio Grande do Norte - área de influência dos rios Curimataú e Guajú (3).

\begin{tabular}{l|c|c|c}
\hline Estimativas & \multicolumn{3}{|c}{ Regiões } \\
\hline & 1 & 2 & 3 \\
$\mathrm{~b}$ & 0,528 & 0,547 & 0,546 \\
$\mathrm{n}$ & 14 & 17 & 21 \\
$\mathrm{~F}_{\text {cal }}$ & & 0,407 & \\
$\mathrm{~F}_{\text {crit }}$ & & 3,20 & \\
\hline Conclusão & aceita $\mathrm{H}_{\mathrm{o}}$ & \\
\hline
\end{tabular}

Tabela 10 - Súmula dos testes F e Mult Range Test (Neuman Keuls), para comparação de coeficientes angulares da regressão PA/CA estimadas para machos e fêmeas do camarão sete-barbas, Xiphopenaeus kroyeri (Heller, 1862), capturados nos estados de Sergipe e Alagoas - área de influência do rio São Francisco (1), Pernambuco área de influência dos rios Formoso e Ilhetas (2) e Rio Grande do Norte - área de influência dos rios Curimataú e Guajú (3).

\begin{tabular}{l|c|c|c}
\hline Estimativas & \multicolumn{3}{|c}{ Regiões } \\
\hline & 1 & 2 & 3 \\
$\mathrm{~b}$ & 3,010 & 3,046 & 3,068 \\
$\mathrm{n}$ & 14 & 17 & 21 \\
$\mathrm{~F}_{\text {cal }}$ & & 0,240 & \\
$\mathrm{~F}_{\text {crit }}$ & & 3,20 & \\
\hline Conclusão & aceita $\mathrm{H}_{\mathrm{o}}$ & \multicolumn{2}{c}{} \\
\hline
\end{tabular}

A hipótese de nulidade do teste $\mathrm{F}(\alpha=0,05)$ foi rejeitada para as equações a seguir, de modo a se afirmar que pelos menos dois dos coeficientes angulares das equações estimados para dados provenientes das áreas consideradas apresentam coeficientes angulares diferentes.

(a) comprimento total - CT /comprimento de cefalotórax - CC (tabela 11)

A aceitação da hipótese de nulidade do teste Neuman Keuls $(q=0,05)$, quando se compara os coeficientes angulares das equações acima, indica não existir diferença estatística significante entre os coeficientes angulares estimados com dados provenientes da área de influência do rio São Francisco e da área de influência dos rios Mamucabas e Ilhetas. O mesmo teste, entretanto, permite que se conclua pela rejeição da hipótese de nulidade quando se compara o coeficiente angular da equação resultante de dados provenientes da área de influência dos

Trab. Oceanog. Univ. Fed. PE, Recife, 27(1):129- 148, 1999. 
rios Curimataú e Gurjaú com os coeficientes das equações provenientes da área de influência dos rios Mamucabas e Ilhetas e área de influência do rio São Francisco, sendo o coeficiente da equação obtida com dados área de influência dos rios Curimataú e Gurjaú maior para os dois casos.

(b) Comprimento do abdome - CA/comprimento do cefalotórax - CC (tabela 12)

A aceitação da hipótese de nulidade do teste Neuman Keuls $(q=0,05)$, quando se compara os coeficientes angulares das equações acima, indica não existir diferença estatística significante entre os coeficientes angulares estimados com dados provenientes da área de influência do rio São Francisco e área de influência dos rios Mamucabas e Ilhetas. O mesmo teste, entretanto, permite que se conclua pela rejeição da hipótese de nulidade quando se compara o coeficiente angular da equação resultante de dados provenientes da área de Baia Formosa com os coeficientes das equações provenientes da área de influência do rio São Francisco e da área de influência dos rios Mamucabas e Ilhetas, sendo o coeficiente da equação obtida com dados da área de influência dos rios Curimataú e Guajú maior para os dois casos.

Tabela 11 - Súmula dos testes F e Mult Range Test (Neuman Keuls), para comparação de coeficientes angulares da regressão CT/CC estimadas para machos e fêmeas do camarão sete-barbas, Xiphopenaeus kroyeri (Heller, 1862), capturados nos estados de Sergipe e Alagoas - área de influência do rio São Francisco (1), Pernambuco - área de influência dos rios Formoso e Ilhetas (2) e Rio Grande do Norte - área de influência dos rios Curimataú e Guajú (3).

\begin{tabular}{|c|c|c|c|}
\hline Estimativas & \multicolumn{3}{|c|}{ Regiões } \\
\hline $\begin{array}{l}\text { Teste F } \\
\mathrm{b} \\
\mathrm{n} \\
\mathrm{F}_{\text {cal }} \\
\mathrm{F}_{\text {crit }} \\
\end{array}$ & $\begin{array}{c}1 \\
3,507 \\
14\end{array}$ & $\begin{array}{c}2 \\
3,510 \\
17 \\
6,603 \\
3,20 \\
\end{array}$ & $\begin{array}{c}3 \\
3,887 \\
21\end{array}$ \\
\hline $\begin{array}{l}\text { Conclusão } \\
\text { Mult Range Test } \\
\text { Diferença entre b's } \\
\text { SE } \\
\mathrm{q}_{\mathrm{cal}} \\
\mathrm{q}_{\text {crit }} \\
\text { Conclusão } \\
\end{array}$ & $\begin{array}{c}\text { Rejeita } \mathrm{H}_{\mathrm{o}} \\
3-1 \\
0,380 \\
0,102 \\
3,737 \\
3,442 \\
\text { rejeita } \mathrm{H}_{\mathrm{o}}\end{array}$ & $\begin{array}{c}3-2 \\
0,377 \\
0,083 \\
4,659 \\
2,858 \\
\text { rejeita } \mathrm{H}_{\mathrm{o}}\end{array}$ & $\begin{array}{c}2-1 \\
0,003 \\
0,112 \\
0,027 \\
2,858 \\
\text { aceita } \mathrm{H}_{\mathrm{o}}\end{array}$ \\
\hline
\end{tabular}

Tabela 12 - Súmula dos testes F e Mult Range Test (Neuman Keuls), para comparação de coeficientes angulares da regressão CA/CC estimadas para machos e fêmeas do camarão sete-barbas, Xiphopenaeus kroyeri (Heller, 1862), capturados nos estados de Sergipe e Alagoas - área de influência do rio São Francisco (1), Pernambuco - área de influência dos rios Formoso e Ilhetas (2) e Rio Grande do Norte - área da baia Formosa área de influência dos rios Curimataú e Guajú (3).

\begin{tabular}{l|l|l|l}
\hline Estimativas & \multicolumn{3}{|c}{ Regiões } \\
\hline Teste F & 1 & 2 & 3 \\
\hline 144
\end{tabular}




\begin{tabular}{|c|c|c|c|}
\hline $\begin{array}{l}\mathrm{b} \\
\mathrm{n} \\
\mathrm{F}_{\text {cal }} \\
\mathrm{F}_{\text {crit }}\end{array}$ & $\begin{array}{c}1,853 \\
14\end{array}$ & $\begin{array}{c}1,920 \\
17 \\
4,470 \\
3,20 \\
\end{array}$ & $\begin{array}{c}2,121 \\
21\end{array}$ \\
\hline $\begin{array}{l}\text { Conclusão } \\
\text { Mult Range }\end{array}$ & $\begin{array}{c}\text { Rejeita } \mathrm{H}_{\mathrm{o}} \\
3-1\end{array}$ & $3-2$ & $2-1$ \\
\hline $\begin{array}{l}\text { Test } \\
\text { Diferença } \\
\text { entre b's }\end{array}$ & 0,268 & 0,201 & 0,067 \\
\hline SE & 0,076 & 0,062 & 0,084 \\
\hline $\mathrm{q}_{\mathrm{cal}}$ & 3,507 & 3,241 & 0,800 \\
\hline $\mathrm{q}_{\text {crit }}$ & 3,442 & 2,858 & 2,858 \\
\hline Conclusão & rejeita $\mathrm{H}_{\mathrm{o}}$ & rejeita $\mathrm{H}_{\mathrm{o}}$ & aceita $\mathrm{H}_{\mathrm{o}}$ \\
\hline
\end{tabular}

(c) - Peso do cefalotórax - PC/comprimento do cefalotórax - CC (tabela 13)

A rejeição da hipótese de nulidade do teste Neuman Keuls $(q=0,05)$ quando se compara os coeficientes angulares das equações estimadas para as áreas em estudo, indica existir diferença estatística significante entre os mesmos, estando os coeficientes distribuídos por área, em ordem decrescente como a seguir - área de influência dos rios Curimataú e Guajú, área de influência dos rios Mamucabas e Ilhetas e área de influência do rio São Francisco.

Tabela 13 - Súmula dos testes F e Mult Range Test (Neuman Keuls), para comparação de coeficientes angulares da regressão PC/CC estimadas para machos e fêmeas do camarão sete-barbas, Xiphopenaeus kroyeri (Heller, 1862), capturados nos estados de Sergipe e Alagoas - área de influência do rio São Francisco (1), Pernambuco - área de influência dos rios Formoso e Ilhetas (2) e Rio Grande do Norte - área de influência dos rios Curimataú e Guajú (3).

\begin{tabular}{l|c|c|c}
\hline Estimativas & \multicolumn{3}{|c}{ Regiões } \\
\hline Teste F & 1 & 2 & 3 \\
$\mathrm{~b}$ & 2,526 & 2,886 & 2,705 \\
$\mathrm{n}$ & 14 & 17 & 21 \\
$\mathrm{~F}_{\text {cal }}$ & & 8,712 & \\
$\mathrm{~F}_{\text {crit }}$ & \multicolumn{3}{|}{} \\
\hline Conclusão & $2-1$ & $2-3$ & $1-3$ \\
Mult Range Test & 0,340 & 0,161 & 0,179 \\
Diferença entre b's & 0,058 & 0,045 & 0,049 \\
SE & 5,902 & 3,609 & 3,663 \\
$\mathrm{q}_{\text {cal }}$ & 3,442 & 2,858 & 2,858 \\
$\mathrm{q}_{\text {crit }}$ & Rejeita $\mathrm{H}_{\mathrm{o}}$ & rejeita $\mathrm{H}_{\mathrm{o}}$ \\
Conclusão & \multicolumn{3}{c}{} \\
\hline
\end{tabular}

(d) Peso total - PT/comprimento do cefalotórax - CC (Tabela 14)

Trab. Oceanog. Univ. Fed. PE, Recife, 27(1):129- 148, 1999. 
A rejeição da hipótese de nulidade do teste Neuman Keuls $(q=0,05)$ quando se compara os coeficientes angulares das equações estimadas para as áreas em estudo, indica existir diferença estatística significante entre os mesmos, estando os coeficientes distribuídos por área, em ordem decrescente como a seguir - área de influência dos rios Curimataú e Guajú, área de influência dos rios Mamucabas e Ilhetas e área de influência do rio São Francisco. 
Tabela 14 - Súmula dos testes F e Mult Range Test (Neuman Keuls), para comparação de coeficientes angulares da regressão PT/CC estimadas para machos e fêmeas do camarão sete-barbas, Xiphopenaeus kroyeri (Heller, 1862), capturados nos estados de Sergipe e Alagoas - área de influência do rio São Francisco (1), Pernambuco - área de influência dos rios Formoso e Ilhetas (2) e Rio Grande do Norte - área de influência dos rios Curimataú e Guajú (3).

\begin{tabular}{l|c|c|c}
\hline Estimativas & \multicolumn{3}{|c}{ Regiões } \\
\hline Teste $\mathrm{F}$ & 1 & 2 & 3 \\
$\mathrm{~b}$ & 2,342 & 2,524 & 2,667 \\
$\mathrm{n}$ & 14 & 17 & 21 \\
$\mathrm{~F}_{\text {cal }}$ & \multicolumn{3}{|c}{} \\
$\mathrm{F}_{\text {crit }}$ & 24,183 & $2-1$ \\
\hline Conclusão & Rejeita $\mathrm{H}_{\mathrm{o}}$ & 3,20 & 0,182 \\
\hline Mult Range Test & $3-1$ & $3-2$ & 0,042 \\
Diferença entre b's & 0,325 & 0,143 & 4,380 \\
SE & 0,035 & 0,032 & 2,858 \\
qcal $_{\text {qcrit }}$ & 9,221 & 4,444 & rejeita $\mathrm{H}_{\mathrm{o}}$ \\
Conclusão & 3,442 & 2,858 & \\
\hline
\end{tabular}

(e) Peso do abdome - PA/peso do cefalotórax - CC (tabela 15)

A aceitação da hipótese de nulidade do teste Neuman Keuls $(q=0,05)$, quando se compara os coeficientes angulares das equações acima, indica não existir diferença estatística significante entre os coeficientes angulares estimados com dados provenientes da área de influência dos rios Mamucabas e Ilhetas e da área de influência do rio São Francisco. O mesmo teste, entretanto, permite que se conclua pela rejeição da hipótese de nulidade quando se compara o coeficiente angular da equação resultante de dados provenientes da área de influência dos rios Curimataú e Guajú com os coeficientes das equações provenientes da área de influência do rio São Francisco e da área de influência dos rios Mamucabas e Ilhetas, sendo o coeficiente da equação obtido com dados da área de influência dos rios Curimataú e Guajú maior para os dois os casos.

(f) Comprimento do abdome - CA/comprimento total - CT (tabela 16)

A aceitação da hipótese de nulidade do teste Neuman Keuls $(q=0,05)$, quando se compara os coeficientes angulares das equações acima, indica não existir diferença estatística significante entre os coeficientes angulares estimados com dados provenientes da área de influência do rio São Francisco e da área de influência dos rios Curimataú e Guajú. O mesmo teste, entretanto, permite que se conclua pela rejeição da hipótese de nulidade quando se compara o coeficiente angular da equação resultante de dados provenientes da da área de influência dos rios Mamucabas e Ilhetas com os coeficientes das equações provenientes da área de influência do rio São Francisco e da área de área de influência dos rios

Trab. Oceanog. Univ. Fed. PE, Recife, 27(1):129- 148, 1999. 
Curimataú e Guajú, sendo o coeficiente da equação obtida com dados da área de influência dos rios Mamucabas e Ilhetas maior para os dois os casos. 
Tabela 15 - Súmula dos testes F e Mult Range Test (Neuman Keuls), para comparação de coeficientes angulares da regressão PA/CC estimadas para machos e fêmeas do camarão sete-barbas, Xiphopenaeus kroyeri (Heller, 1862), capturados nos estados de Sergipe e Alagoas - área de influência do rio São Francisco (1), Pernambuco - área de influência dos rios Formoso e Ilhetas (2) e Rio Grande do Norte - área de influência dos rios Curimataú e Guajú (3).

\begin{tabular}{l|c|c|c}
\hline Estimativas & \multicolumn{3}{|c}{ Regiões } \\
\hline Teste F & 1 & 2 & 3 \\
$\mathrm{~b}$ & 2,222 & 2,316 & 2,657 \\
$\mathrm{n}$ & 14 & 17 & 21 \\
$\mathrm{~F}_{\text {cal }}$ & \multicolumn{3}{|c}{} \\
$\mathrm{F}_{\text {crit }}$ & 22,044 & \\
\hline Conclusão & Rejeita $\mathrm{H}_{\mathrm{o}}$ & $2-20$ \\
Mult Range Test & $3-1$ & $3-2$ & 0,094 \\
Diferença entre b's & 0,435 & 0,341 & 0,065 \\
SE & 0,055 & 0,050 & 1,454 \\
qcal & 7,931 & 6,810 & 2,858 \\
qcrit & 3,442 & 2,858 & aceita $\mathrm{H}_{\mathrm{o}}$ \\
Conclusão & rejeita $\mathrm{H}_{\mathrm{o}}$ & rejeita $\mathrm{H}_{\mathrm{o}}$ & \\
\hline
\end{tabular}

Tabela 16 - Súmula dos testes $\mathrm{F}$ e Mult Range Test (Neuman Keuls), para comparação de coeficientes angulares da regressão PT/CT estimadas para machos e fêmeas do camarão sete-barbas, Xiphopenaeus kroyeri (Heller, 1862), capturados nos estados de Sergipe e Alagoas - área de influência do rio São Francisco (1), Pernambuco área de influência dos rios Formoso e Ilhetas (2) e Rio Grande do Norte - área de influência dos rios Curimataú e Guajú (3).

\begin{tabular}{l|c|c|c}
\hline Estimativas & \multicolumn{3}{|c}{ Regiões } \\
\hline Teste F & 1 & 2 & 2 \\
$\mathrm{~b}$ & 3,025 & 3,245 & 3,085 \\
$\mathrm{n}$ & 14 & 17 & 21 \\
$\mathrm{~F}_{\text {cal }}$ & \multicolumn{3}{|c}{} \\
$\mathrm{F}_{\text {crit }}$ & 3,578 & \\
\hline Conclusão & \multicolumn{3}{|c}{} \\
Mult Range Test & $2-1$ & $2-3$ & $3-1$ \\
Diferença entre & 0,220 & 0,160 & 0,060 \\
$\mathrm{~b}$ 's & \multicolumn{3}{|c}{} \\
$\mathrm{SE}$ & 0,065 & 0,048 & 0,054 \\
$\mathrm{q}_{\text {cal }}$ & 3,407 & 3,308 & 1,117 \\
$\mathrm{q}_{\text {crit }}$ & 3,442 & 2,858 & 2,858 \\
Conclusão & rejeita $\mathrm{H}_{\mathrm{o}}$ & rejeita $\mathrm{H}_{\mathrm{o}}$ & aceita $\mathrm{H}_{\mathrm{o}}$ \\
\hline
\end{tabular}

\section{CONCLUSÕES}

Em geral, no Nordeste brasileiro, as fêmeas de Xiphopenaeus kroyeri Trab. Oceanog. Univ. Fed. PE, Recife, 27(1):129- 148, 1999. 
são maiores e mais pesadas do que os machos.

Indivíduos capturados na área de influência do rio São Francisco e na área de influência dos rios Mamucabas e Ilhetas possuem, em geral, comprimentos e pesos médios estatisticamente iguais. Os indivíduos capturados na área de influência dos rios Curimataú e Guajú são estatisticamente menores e menos pesados do que os indivíduos capturados nas demais áreas.

Os altos valores do coeficiente de correlação confirmam a existência de crescimento isométrico entre medidas de comprimento e alométrico entre medidas de peso e comprimento para o camarão sete-barbas capturados nas área de influência do rio São Francisco, área de influência dos rios Mamucabas e Ilhetas e área de influência dos rios Curimataú e Guajú.

Em geral, os coeficientes angulares das equações estimadas para correlacionar medidas de comprimento e medidas de comprimento e peso do camarão sete-barbas, independente de sexo, capturados nas áreas influência do rio São Francisco e rios Mamucabas e Ilhetas são maiores do que os coeficientes angulares das equações estimadas para as indivíduos capturados na área de influência dos rios Curimataú e Guajú.

\section{REFERÊNCIAS BIBLIOGRÁFICAS}

ALVERSON, D. L., FREEBERG, M. H., POPE, J. G. \& MURAWSKI, S. A. A global assessment of fisheries bycatch and discards. FAO Fisheries Technical Paper, Rome, N0. 339. 233p.

AMADO, M. A. P. M. Estudos biológicos do Xiphopenaeus kroyeri (Heller, 1862), camarão sete-barbas (Crustacea, Penaeidae) de Matinhos, PR. Paraná, 1978. 100p. Universidade Federal do Paraná (Dissertação Mestrado).

CARVALHO, R. C. A., OLIVEIRA, M.Y.S. \& CAMPOS, L. M. A. Análise dos custos e rentabilidade da captura e beneficiamento de camarão nos estados de Pernambuco e Alagoas, Nordeste do Brasil (no prelo).

COELHO, P. A., RAMOS-PORTO, M. \& KOENING, M. L. Biogeografia e bionomia dos crustáceos do litoral equatorial brasileiro. Trabalhos Oceanográficos da Universidade Federal de Pernambuco, Recife, v. 15, p. 7138, 1980.

COELHO, P. A.\& SANTOS, M. C. F. Época da reprodução do camarão setebarbas, Xiphopenaeus kroyeri (Heller, 1862) (Crustacea, Decapoda, Penaeidae) na região de Tamandaré, PE. Boletim Técnico Científico do CEPENE, Rio Formoso, v. 1, n. 1, p. 171-186, 1993.

--- \& ---. A pesca de camarões marinhos ao largo da foz do São Francisco (AL/SE). Trabalhos Oceanográficos da Universidade Federal de Pernambuco, Recife, v. 24, p. 149-161, 1994/95.

D'INCAO, F. Taxonomia, padrões distribucionais e ecológicos dos Dendrobranchiata (Crustacea: Decapoda) do Brasil e Atlântico Ocidental. Curitiba, 1995. 365p. Universidade Federal do Paraná (Doutorado em Ciências). GULLAND, J. A. \& ROTHSCHILD, B. J. Penaeid shrimps : their biology and 
management. 1984. England. Fishing News Books, Farnham, Surrey, England, 308p.

IBAMA/CEPENE. Estatística da pesca em 1997 - Brasil - Grandes regiões e unidades da Federação. Tamanda're, 1998. 110p.

IVO, C. T. C. \& FONTELES-FILHO, A. A. Estatística pesqueira - Aplicação em Engenharia de Pesca Ceará. Tom Gráfica Editora, 1997, vi+193pp.

IVO, C. T. C. \& PEREIRA, J. A. Sinopse das principais observações sobre as lagostas Panulirus argus e Panulirus laevicauda capturadas em águas costeiras do Brasil, entre os Estados do Amapá e do Espírito Santo. Boletim Técnico Científico do CEPENE, Tamandaré, v. 4, n. 1, p. 7-94, 1996.

MOTA-AMADO, M. A. P. Crescimento, idade e reprodução do camarão sete barbas Xiphopenaeus kroyeri (Heller, 1862) (Crustacea, Penaeidae) do litoral sul de Pernambuco. In: ENCONTRO DE ZOOLOGIA, 15, 1988, Curitiba. Resumos..., Curitiba, 1988, p. 110.

NEIVA, G. S. \& WISE, J. P. A biologia e pesca do «camarão sete barbas» da baía de Santos, Brasil. Revista Nacional da Pesca, São Paulo, p. 12-19, 1967.

PAIVA, M. P. Levantamento do estado da arte da pesquisa dos recursos vivos marinhos do Brasil. Brasília : Ministério do Meio Ambiente, dos Recursos Hídricos e da Amazônia Legal - Programa REVIZEE, 1996, 241p.

PAIVA, M. P. Recursos pesqueiros estuarinos e marinhos do Brasil. Fortaleza, EUFC, 1997, 278 p.

RODRIGUES, E. S., PITA, J. B., LOPES, R. da G., COELHO, J. A. P. \& PUZZI, A. Aspectos biológicos e pesqueiros do camarão sete-barbas (Xiphopenaeus kroyeri) capturado pela pesca artesanal no litoral do Estado de São Paulo. Boletim do Instituto de Pesca, São Paulo, v. 19, p. 67-81, 1992.

SALES, R. Identificação de estoques do pargo, Lutjanus purpureus Poey, nas regiões Norte e Nordeste do Brasil, entre $4^{\circ}$ W e 49 ${ }^{\circ}$ W. 1997. Universidade Federal do Ceará (Mestrado em Engenharia de Pesca). Fortaleza, 91p.

SANTOS, M. C. F. O camarão sete-barbas, Xiphopenaeus kroyeri (Heller, 1862) (Crustacea, Decapoda, Penaeidae) no Nordeste do Brasil. 1997. Universidade Federal de Pernambuco (Mestrado em Oceanografia Biológica). Recife, 232p.

ZAR, J. H. Biostatistical analyses. England Cliffs. Prentice-Hall Inc, 1984, 620p. 